\title{
BMJ Open Preventing type 2 diabetes: systematic review of studies of cost-effectiveness of lifestyle programmes and metformin, with and without screening, for pre- diabetes
}

\author{
Samantha Roberts, ${ }^{1}$ Eleanor Barry, ${ }^{1}$ Dawn Craig, ${ }^{2}$ Mara Airoldi, ${ }^{3}$ Gwyn Bevan, ${ }^{3}$ \\ Trisha Greenhalgh ${ }^{1}$
}

To cite: Roberts S, Barry E, Craig D, et al. Preventing type 2 diabetes: systematic review of studies of costeffectiveness of lifestyle programmes and metformin, with and without screening, for pre-diabetes. BMJ Open 2017;7:e017184. doi:10.1136/ bmjopen-2017-017184

- Prepublication history and additional material for this paper are available online. To view these files, please visit the journal online (http://dx.doi. org/10.1136/bmjopen-2017017184).

Received 6 April 2017 Revised 20 June 2017 Accepted 21 June 2017

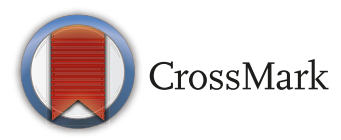

${ }^{1}$ Nuffield Department of Primary Care Health Sciences, Radcliffe Observatory Quarter, University of Oxford, Oxford, UK

${ }^{2}$ Institute of Health \& Society, University of Newcastle, Newcastle upon Tyne, UK ${ }^{3}$ Blavatnik School of Government, Radcliffe Observatory Quarter, Woodstock Road, University of Oxford, Oxford, UK

Correspondence to Dr Samantha Roberts; samantha.roberts@gtc.ox.ac.uk

\section{ABSTRACT}

Objective Explore the cost-effectiveness of lifestyle interventions and metformin in reducing subsequent incidence of type 2 diabetes, both alone and in combination with a screening programme to identify highrisk individuals.

Design Systematic review of economic evaluations. Data sources and eligibility criteria Database searches (Embase, Medline, PreMedline, NHS EED) and citation tracking identified economic evaluations of lifestyle interventions or metformin alone or in combination with screening programmes in people at high risk of developing diabetes. The International Society for Pharmacoeconomics and Outcomes Research's Questionnaire to Assess Relevance and Credibility of Modelling Studies for Informing Healthcare Decision Making was used to assess study quality.

Results 27 studies were included; all had evaluated lifestyle interventions and 12 also evaluated metformin. Primary studies exhibited considerable heterogeneity in definitions of pre-diabetes and intensity and duration of lifestyle programmes. Lifestyle programmes and metformin appeared to be cost effective in preventing diabetes in high-risk individuals (median incremental cost-effectiveness ratios of $£ 7490$ /quality-adjusted lifeyear (QALY) and £8428/QALY, respectively) but economic estimates varied widely between studies. Intervention-only programmes were in general more cost effective than programmes that also included a screening component. The longer the period evaluated, the more cost-effective interventions appeared. In the few studies that evaluated other economic considerations, budget impact of prevention programmes was moderate $(0.13 \%-0.2 \%$ of total healthcare budget), financial payoffs were delayed (by 9-14 years) and impact on incident cases of diabetes was limited $(0.1 \%-1.6 \%$ reduction). There was insufficient evidence to answer the question of (1) whether lifestyle programmes are more cost effective than metformin or (2) whether low-intensity lifestyle interventions are more cost effective than the more intensive lifestyle programmes that were tested in trials.

Conclusions The economics of preventing diabetes are complex. There is some evidence that diabetes prevention programmes are cost effective, but the evidence base

\section{Strengths and limitations of this study}

- To our knowledge, this is the largest and most up-todate summary of economic evaluations of diabetes prevention programmes and the only one to include comparison with metformin and consideration of relevance and credibility for policymakers. We undertook a detailed analysis of assumptions underpinning modelling studies and compared these with findings from clinical trials.

- Limitations are the small number of economic evaluations included that reflect prevailing national policy and the preponderance of studies from wealthy developed countries.

to date provides few clear answers regarding design of prevention programmes because of differences in denominator populations, definitions, interventions and modelling assumptions.

\section{INTRODUCTION}

Diabetes is a global health priority, with 415 million known adult cases worldwide, of which $91 \%$ are type 2 diabetes. ${ }^{1}$ Ageing of the population is predicted to drive substantial increases in prevalence (estimated to 642 million by 2040), ${ }^{2}$ with particularly rapid increases in low-and-middle-income countries. ${ }^{3}$ The burden of complications in diabetes is high, including heart disease, stroke, neuropathy, nephropathy and retinopathy. ${ }^{4}$ Type 2 diabetes develops as a result of genetic, environmental and behavioural factors, including sedentary lifestyle and energy-rich, nutrient-poor diet, both of which predispose to obesity.

Diabetes takes a significant toll on health budgets around the world, accounting for $5 \%-20 \%$ of total healthcare expenditure 
in many countries. ${ }^{1}$ Both absolute costs and proportion of overall health budget for type 2 diabetes are set to increase further in future decades as prevalence rises, in the context of a marked reduction in the proportion of the population who are economically active (eg, in the UK, the relative economic burden per worker is expected to increase by $40 \%-50 \%$ by $\left.2060^{6}\right)$. Cost-effective treatment and prevention strategies, with acceptable budget impact, will therefore become increasingly important as resources become stretched.

\section{Types of pre-diabetes}

Type 2 diabetes is often preceded by a phase of abnormal glucose regulation (pre-diabetes). Pre-diabetes is a generic term that includes impaired fasting glucose (IFG), impaired glucose tolerance (IGT) and HbAlc in the 'at risk' range. ${ }^{7}$ One individual may have one, two or all of these types of pre-diabetes. Table 1 describes these different pre-diabetic states, how they are diagnosed and current diagnostic guidelines. ${ }^{8-10}$ The distinction between types of pre-diabetes is important for a number of reasons. First, different definitions of pre-diabetes are associated with distinct physiological changes. IFG is associated with reduced hepatic insulin sensitivity and first-phase insulin response; IGT is associated with reduced peripheral insulin sensitivity and second-phase insulin response and HbAlc reflects aggregated blood glucose levels over time. ${ }^{11}$ Second, progression to diabetes ranges from $3.6 \%$ to $7.0 \%$ annually depending on the type of pre-diabetes. ${ }^{12}$ Third, IGT is associated with increased risk of microvascular disease, whereas the relationship is less clear for other types of pre-diabetes. ${ }^{7}$ Finally, there is evidence that people with different types of pre-diabetes respond differently to the same intervention. For example, in a large US trial, the US Diabetes Prevention Program (USDPP), lifestyle programmes were less effective and metformin more effective in participants with IGT, IFG and HbAlc in the 'at-risk range' compared with the entire cohort which were identified on the basis of IGT and IFG. ${ }^{13}$

\section{Types of screening and prevention programmes}

Pre-diabetes is almost always asymptomatic. It tends to be diagnosed incidentally (when blood tests are performed for other reasons) or as part of a proactive screening programme delivered either to an entire population or to selected individuals. Most commonly, screening blood tests are offered to people identified as at high risk of developing diabetes based on demographic variables (eg, age, ethnicity), survey questions (eg, family history of diabetes, personal history of gestational diabetes) or biomarkers (eg, body mass index (BMI), blood pressure), typically combined in a 'diabetes risk score'. ${ }^{14}$ People diagnosed with pre-diabetes may be offered a lifestyle programme (to encourage a healthy diet and increased physical activity) or metformin. These interventions have been shown to delay or prevent type 2 diabetes in a significant proportion of participants in large randomised trials in the USA ${ }^{15}$ Europe ${ }^{16}$ China $^{17}$ and India. ${ }^{18}$ Lifestyle

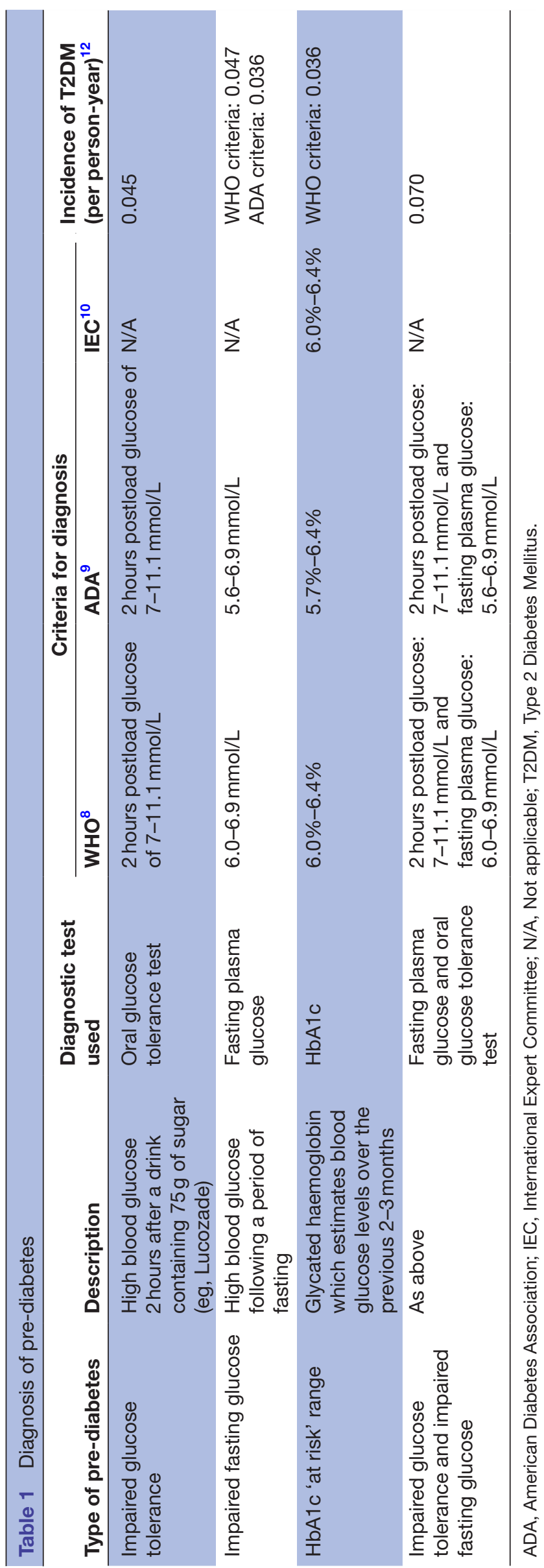


programmes in these trials were intensive and sustained: 3-10 years of individual and group sessions provided by specialist staff (dieticians or exercise physiologists with annual physician review). Subsequent translation of these findings into large-scale community-based programmes produced interventions that were both shorter (3-12 months) and less intense (eg, they offered less sessions and were delivered to groups rather than individuals by non-specialist staff such as lay workers or prevention managers). These large-scale community-based programmes have been offered to populations of similar age and BMI to the large trials but with different selection criteria (eg, selection based on elements of the metabolic syndrome rather than the criteria of IGT seen in the large trials). ${ }^{19}$ There is some evidence that these pragmatic interventions offered to a real-world population deliver more limited and less sustained benefits than were seen with more intensive interventions in trial populations. ${ }^{20}$

Given the potential impact on populations and health budgets, the burden of type 2 diabetes is a key issue for policymakers. In response, a number of countries, including the USA and the UK, are developing (or seeking to develop) national diabetes prevention programmes. ${ }^{21} 22$ The design of large-scale prevention programmes incorporates a number of important choices: (1) whether to screen a portion of the population for diabetes risk or focus on people who are already known to have pre-diabetes; (2) if no screening programme is in place, how to identify participants who may benefit from a diabetes prevention programme; (3) the role of different types of interventions (lifestyle programmes or metformin) and (4) the optimum intensity and duration of the programme.

This study was designed to help inform decision-making by local and national policymakers and health insurers in countries with a high and/or rising incidence of type 2 diabetes. Our research question were

1. What is the evidence on cost-effectiveness of lifestyle programmes or metformin in diabetes prevention?

2. What is the impact of the following factors on the cost-effectiveness of these interventions?

a. Type of pre-diabetes (IFG, IGT or 'at risk' HbA1c).

b. Intensity of lifestyle intervention: Including three different measures of intensity, each of which was examined separately: (i) frequency of contact in initial 'core' teaching/coaching sessions, (ii) duration of core and maintenance intervention and (iii) group or individual format of sessions.

c. Inclusion of screening: Intervention-only studies on a predefined pre-diabetic or high-risk population or screening for pre-diabetes followed by intervention.

d. Years of follow-up to evaluate diabetes incidence: $<10$ years and $\geq 25$ years.

3. What are the implications of these findings for policymakers and health insurers?

A number of systematic reviews of economic evaluations of diet and exercise in diabetes prevention have been undertaken in the last 10 years. ${ }^{23-27}$ This paper is the first review to consider the cost-effectiveness of metformin and the first review to examine intervention-only and screening-plus-intervention studies separately. In addition, this paper adds to previous reviews by updating the data set with two new primary studies not included in previous systematic reviews ${ }^{28} 29$ and evaluating studies' relevance for decision-making by policymakers and health insurers.

\section{METHODS}

\section{Search strategy and inclusion criteria}

A database search (covering Embase, PreMedline, Medline and NHS EED) for peer-reviewed articles on pre-diabetes and diabetes prevention between 2004 (the year before the publication of the first cost-effectiveness review of the USDPP) and 2014 identified 3833 papers. Search terms are outlined in online supplementary appendix 1 . Citation tracking and screening of references (in included studies and review articles) identified a further 23 papers up to April 2016. Duplicates were removed and abstracts screened by two reviewers (EB, SR). We included studies that reported full economic evaluation (cost-effectiveness, cost-utility or cost-benefit analysis) of (1) lifestyle programmes, (2) metformin or (3) screening in combination with lifestyle programmes and/or metformin against a base case of usual care or no intervention.

To meet our inclusion criteria, economic evaluations needed to have

1. evaluated the treatment of pre-diabetes with either metformin and/or lifestyle programmes (that addressed diet and physical activity);

2. included $\geq 12$ months of intervention and follow-up;

3. quantified outcomes (such as change in quality-adjusted life-years (QALYs), disability-adjusted life-years (DALYs), life-years gained (LYG) or numbers needed to treat to prevent one case of type 2 diabetes);

4. described the method used to classify people as high risk of developing type 2 diabetes (hence eligible for interventions), including: blood tests for pre-diabetes (any in table 1), screening questionnaires, diabetes risk algorithms or presence of particular risk factors.

Review articles were excluded as were articles focusing only on women with a history of gestational diabetes.

Full papers meeting the above criteria were reviewed; data were extracted from included papers (by SR) and data extraction for a third of papers was checked by a second reviewer $(\mathrm{EB})$.

\section{Quality assessment}

A checklist developed by the International Society for Pharmaco-economics and Outcomes Research (the ISPOR-AMCP-NCP questionnaire ${ }^{30}$ ) was used to evaluate the relevance and credibility of modelling studies for decision-making by policymakers. 


\section{Assumptions and calculations}

All the economic evaluations included in this review were cost-effectiveness analyses (including cost-utility analyses), which measure both the cost of the intervention and the impact of the intervention on participants' quality and/ or length of life. ${ }^{31}$ No full cost-benefit analyses were identified. Cost-effectiveness analyses report their results as ratios of incremental costs divided by incremental benefits; in an incremental cost-effectiveness ratio (ICER). Resources to spend on healthcare are finite, so policymakers set a 'willingness-to-pay' threshold against which a treatment's ICER is compared. Historically, the National Institute for Health and Care Excellence (NICE) in the UK has approved new technologies below the willingness-to-pay threshold of $£ 20000-£ 30000 /$ QALY, $^{32}$ the USA has used a threshold of $\$ 50000 / \mathrm{QALY}^{33}$ and WHO has recommended cost less than the per capita gross domestic product of the relevant country per DALY as the threshold. ${ }^{34}$ For this review, we used a willingness-to-pay threshold of £20 000/QALY. This means that if an intervention is below the willingness-to-pay threshold (costs $<£ 20000$ per QALY), the intervention is considered cost effective. If the intervention costs more than the willingness-to-pay threshold, it is considered not cost effective. An intervention is only cost saving if it is more effective and costs less than current treatment.

Costs are reported in British pounds 2015 using purchasing power parity and currency exchange rates from the CCEMG-EPPI-Centre Cost Converter. ${ }^{35}$ Costs of lifestyle interventions were calculated in 2015 British pounds where sufficient data were available on constituent activities and staff involved, drawing on the Personal Social Services Research Unit ${ }^{36}$ for UK staff cost estimates.

ICERs are reported separately for each outcome measure: as either cost saving or $£ /$ QALY gained ( $£ /$ QALY), £/DALY averted (£/DALY) or $£ /$ life-year gained (£/LYG) (box).

ICERs are reported from two different perspectives: health system and societal perspective. The health system perspective includes only direct medical costs such as (1) staff, facilities, medication and consumables costs required for provision of the intervention; and (2) general healthcare of participants. In addition, studies of cost-effectiveness from a societal perspective include some or all elements of (1) indirect costs of the intervention (eg, exercise equipment, food preparation equipment), (2) participant time (travelling to and participating in intervention's activities), (3) lost productivity due to absence from work and (4) disability benefits payments.

Studies were grouped on a number of dimensions to identify key drivers of differences through subgroup analysis. Subgroups examined included: type of pre-diabetes, intensity of lifestyle intervention (defined by number of sessions in 'core' intervention, duration of core and maintenance programme, group vs individual format), inclusion of screening and years of follow-up to evaluate diabetes incidence. Subgroup medians could not be derived for the type of pre-diabetes as the majority
Box Definitions of measures of effectiveness used in included studies ${ }^{93} 94$

Quality-adjusted life-year (QALY)

A measure of the state of health of a person or group in which the benefits, in terms of length of life, are adjusted to reflect the quality of life. One QALY is equal to 1 year of life in perfect health.

\section{Disability-adjusted life-year}

A measure of the impact of a disease or injury in terms of healthy years lost.

\section{Life-years gained}

A measure of the impact of a disease or treatment on the length of life. Years of life are not adjusted to reflect health or disability.

of studies used IGT to identify eligible participants (with or without IFG), and there were two or less studies that reported £/QALY using each of the remaining methods of identification. Therefore, in order to understand the potential significance of the type of pre-diabetes we undertook a meta-analysis of randomised controlled trials of lifestyle programmes for diabetes prevention. Data were extracted from the 22 primary studies that reported diabetes incidence as an end point that were included in three recent systematic reviews of lifestyle programmes in diabetes prevention. ${ }^{37-39}$ Data were analysed in RevMan V.5.3. Due to the heterogeneity of the primary studies, we used a random-effects model and analysed subgroups defined by the trials' inclusion criteria (IFG, IGT, HbA1c or risk score) and duration of the intervention. Forest plots were generated to illustrate the relative risk of diabetes following a lifestyle programme for each of these groups compared with no intervention.

\section{Patient and public involvement}

This review was conceptualised by a multidisciplinary group, including lay members, in Newham, East London. The authors attended regular project meetings of this group, reporting back the results of the review to the rest of the team.

\section{RESULTS}

In total, 42 full papers were reviewed and 15 were excluded for reasons outlined in figure 1.

In total, 27 studies of diabetes prevention programmes with economic evaluations have been published from 15 countries between 2004 and 2016. ${ }^{28}{ }^{29} 40-64$ Six of the economic evaluations were within-trial cost-utility analyses and 21 were modelling studies (16 Markov models, 2 simulation models, 2 decision trees and 1 combination Markov model and decision tree). Within the modelling studies there were a wide range of model structures, parameters and parameter values which in part drive the variability observed in study results. ${ }^{65}$ 


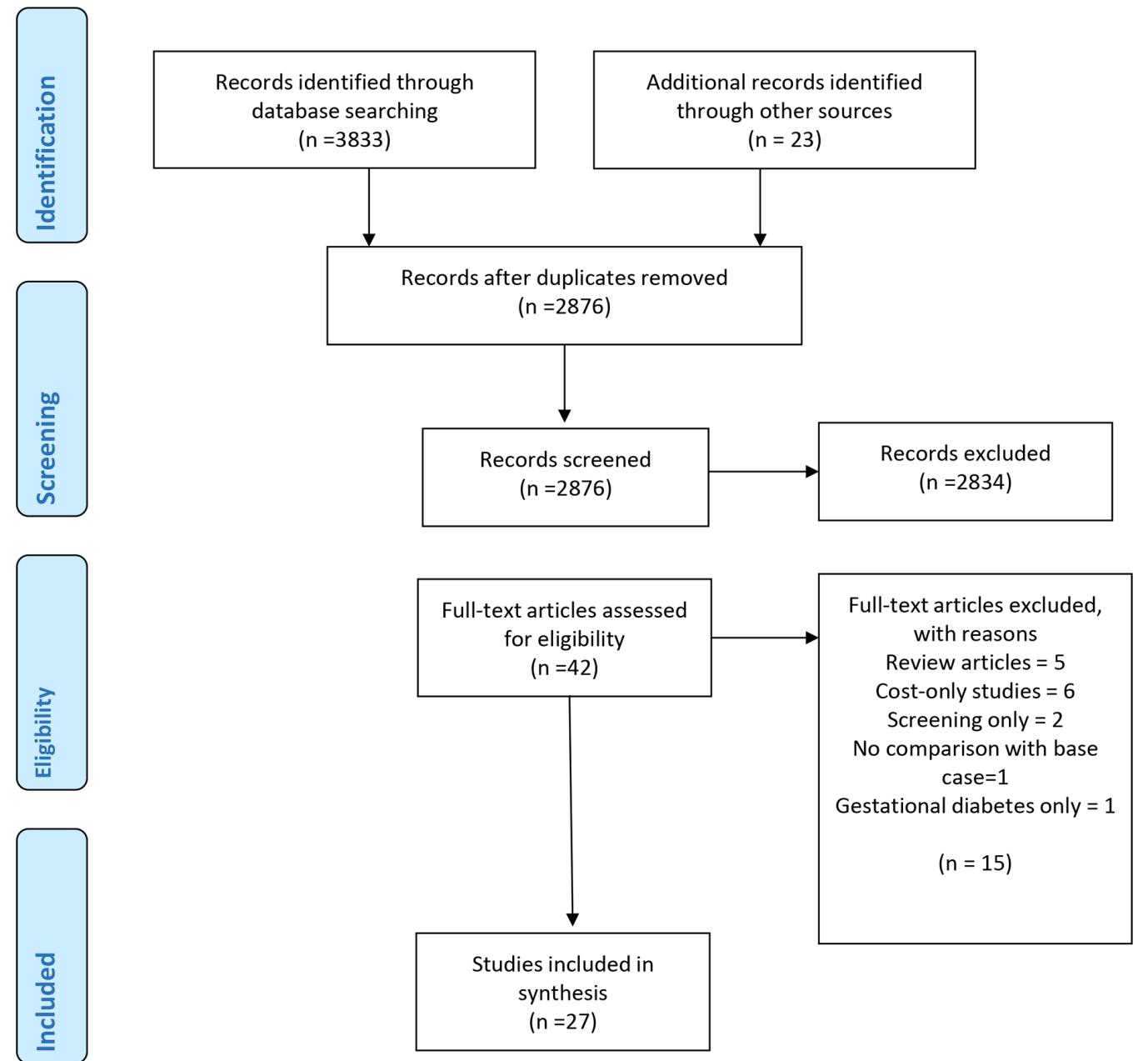

Figure 1 Preferred Reporting Items for Systematic Reviews and Meta-Analyses flow diagram.

\section{Type of intervention}

All 27 studies evaluated lifestyle interventions and 12 also evaluated metformin (online supplementary appendix $2)$. Thirteen reported interventions in a population previously identified as pre-diabetic (people with IFG, IGT or high HbA1c) and 14 reported screening of a broader population and subsequent intervention on those identified as high risk of developing type 2 diabetes. The majority of studies evaluated intensive trial-based interventions, although there was a great deal of heterogeneity in the type of lifestyle interventions evaluated. Table 2 describes some of the dimensions on which lifestyle programmes differed: frequency of contact, duration, staff providing intervention, individual versus group interventions and frequency of contact.

Three studies ${ }^{45} 5459$ did not specify the details of their lifestyle interventions.

\section{Intensive trial-based lifestyle programmes}

In total, 18 of the 24 studies that did describe in detail the lifestyle intervention being evaluated were based on intensive trial-based lifestyle interventions ( 8 based on the USDPP, 4 on the USDPP together with the US Diabetes Prevention Program Outcome Study, 3 on the Finnish Diabetes Prevention Study, 1 on the Da Qing study, 1 on the Indian Diabetes Prevention Programme and 1 on DE-PLAN-CAT). The primary studies were generously resourced, large (300-3000 participants) and provided lengthy interventions (3-10-year duration) including 7-16 initial contacts in the 'core programme' delivered by specialist staff (dieticians, exercise physiologists and annual medical review). Two within-trial studies ${ }^{40} 64$ reported intensive trial-based lifestyle programme costs in sufficient detail for costs to be reconstituted on an activity-based costing basis (online supplementary appendix $3)$. The costs in 2015 British pounds of these interventions were as follows: £2915 per participant over 3 years for the USDPP lifestyle programme, $£ 4001$ per participant over 3 years for the Indian DPP lifestyle programme (excluding staff travel costs).

\section{Translational community-based programmes}

In total, 3 of the 24 studies were based on community translation of these intensive interventions lasting 3-5 years and 3 studies were based on other published studies covering much smaller populations $\quad(<150$ participants) and providing less intensive interventions (ranging from 12 weeks to 1 year in duration), delivered by non-specialist staff (diabetes prevention facilitators and lay workers). 


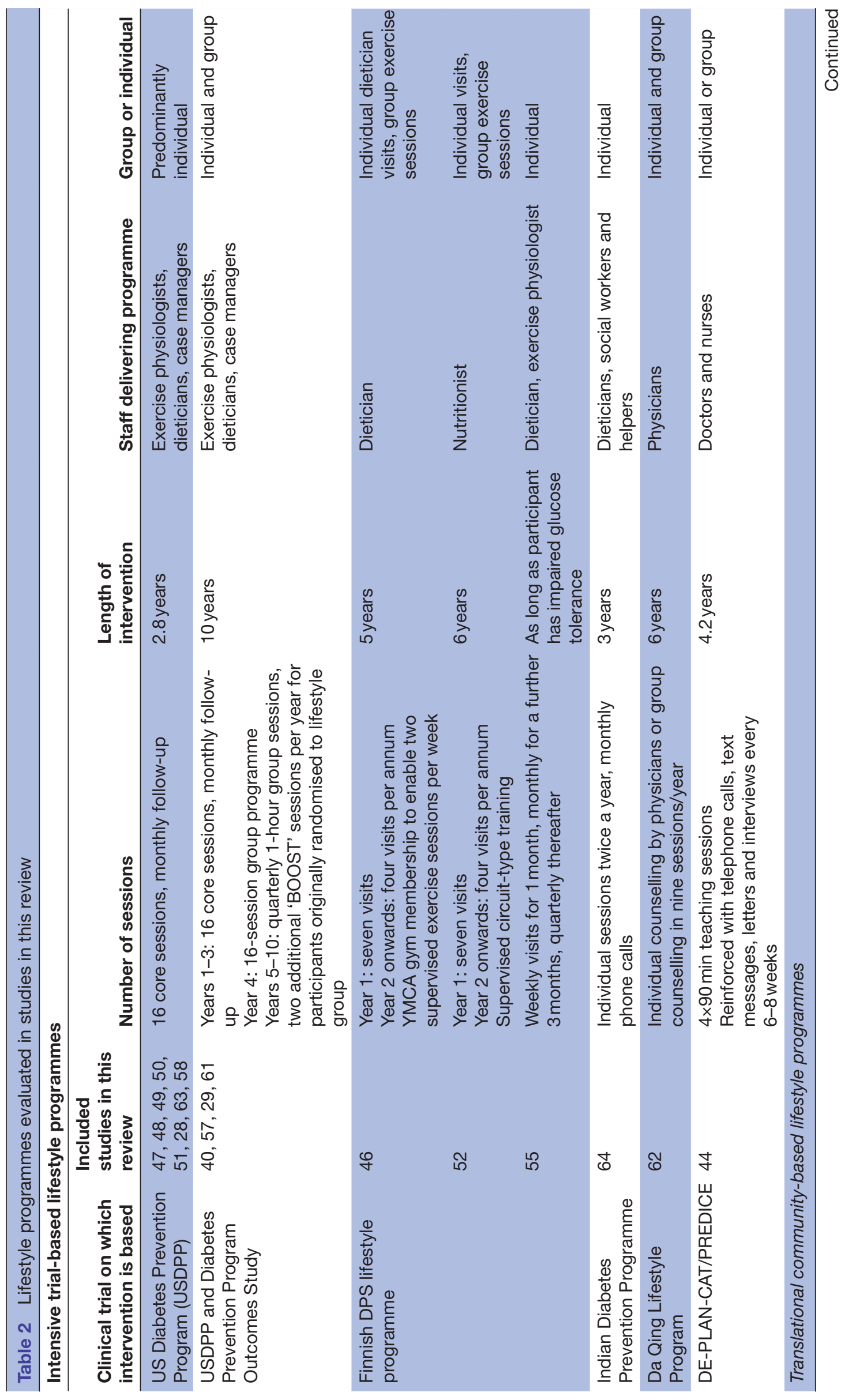

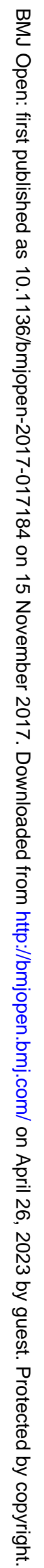




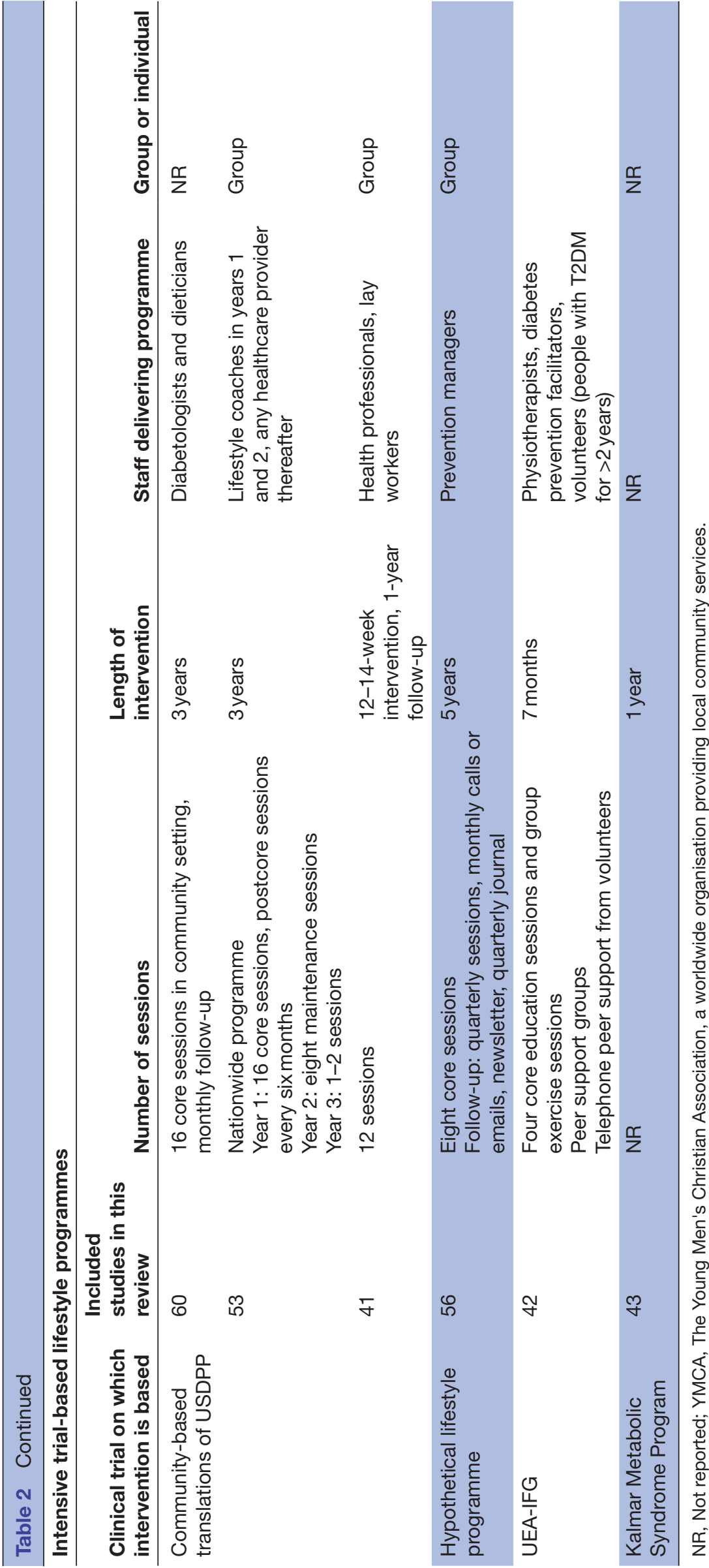

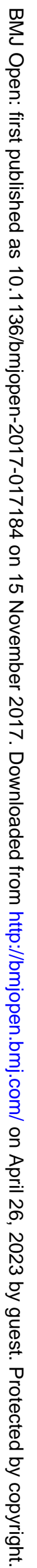




\section{Target population: demographics and type of pre-diabetes}

The target population for 16 of the 27 studies were overweight individuals with IGT, with or without IFG. Four used IFG alone, ${ }^{42} 525663$ two used IGT or IFG, ${ }^{4451}$ one used IFG or HbAlc, ${ }^{53}$ one used HbAlc alone ${ }^{29}$ and three used other methods of screening (such as diabetes risk algorithms, BMI or other elements of metabolic syndrome). ${ }^{41} 4345$ Also, 17 out of 27 studies included participants based on a BMI $\geq 24 \mathrm{~kg} / \mathrm{m}^{2}, 3$ included participants based on a BMI $\geq 30 \mathrm{mg} / \mathrm{kg}^{2}$ and the remainder did not state a BMI cut-off for participation. A wide range of ages (from 18 years and older) were included.

\section{Benefits of interventions}

The primary benefit of diabetes prevention programmes is reduction in incidence of type 2 diabetes and its associated complications, measured in the number needed to treat to delay or prevent a case of diabetes or improvements in QALYs, DALYs and LYG, as summarised in online supplementary appendix 4.

\section{Lifestyle interventions}

In total, 21 studies reported change in QALYs associated with lifestyle interventions with a median 0.159 (range: 0.003-2.91) increase in QALYs and 13 reported LYG with a median increase of 0.30 (range: 0.04-0.84) increase relative to usual care. Four studies reported numbers needed to treat with lifestyle programmes to prevent one case of type 2 diabetes with results ranging from 4.2 to 30 .

\section{Metformin}

Eight studies measured change in QALYs associated with metformin therapy with a median of 0.105 (range: 0.012.83) increase in QALYs and five studies reported increase in LYG with a median gain of 0.14 (range: $0.05-0.3$ ). Two studies reported number needed to treat with metformin to prevent 1 case of type 2 diabetes as 6.9 and 27.9.

\section{Side effects of screening or intervention}

The impact of screening and intervention on length of quality of life was included as a change in incremental QALYs in a number of studies, ${ }^{49-51}$ and three studies modelled the impact of adverse effects explicitly. ${ }^{40} 4757$

\section{Value for money}

Policymakers may consider a range of economic factors when considering a new programme: cost-effectiveness, budget impact, effect on incident cases of the disease and equity of healthcare provision. ${ }^{66}$ All studies included in this review considered cost-effectiveness, reporting ICERs, five described budget impact, two modelled impact on incident cases of diabetes and none considered impact on equity of healthcare provision.

\section{Cost-effectiveness}

Overall, lifestyle interventions and metformin appeared to be cost effective in preventing diabetes in high-risk individuals, as summarised in table 3, though there was wide variation in economic estimates between studies.
Substantial differences in participant selection and intervention design, which reflect the different types of pre-diabetes and different types of interventions, as well as differences in model structure, parameters and parameter values, make comparison between studies difficult.

There is insufficient evidence to suggest that lifestyle interventions or metformin will be cost saving. Out of 27 studies, lifestyle interventions were found to be cost saving in 2 studies from a health system perspective, ${ }^{53}$ cost saving from a health system perspective in some countries but not others in one study ${ }^{47}$ and cost saving from a societal perspective in three studies. ${ }^{52562}$ Of the 12 studies evaluating metformin, 2 studies concluded metformin was cost saving from a health system perspective, ${ }^{40}{ }^{46} 1$ study concluded metformin was cost saving from a health system perspective in some countries but not others ${ }^{47}$ and 2 concluded metformin was cost saving from a societal perspective. ${ }^{4061}$

Lifestyle programmes appear to be cost effective. Of the 16 studies measuring cost-effectiveness as £/QALY, the median ICER from a health system perspective was $£ 7490 /$ QALY (range: cost saving to $£ 134$ 420/QALY). Only two studies reported lifestyle interventions that were not cost effective (costing $>£ 20000$ per QALY); of these, one used a model substantially different in structure to other modelling studies included (the Archimedes model, which analyses changes in biological variables, such as insulin resistance, rather than transitions between disease states, such as pre-diabetes, which are used by other models $)^{48}$ and the other included analysis lasting only 1 year; therefore, the benefits of reduced incidence of diabetes were not included. ${ }^{42}$

Metformin also appears to be cost effective from a health system perspective. Of the seven studies measuring cost-effectiveness as £/QALY, the median ICER from a health system perspective was $£ 8428 /$ QALY (range: cost saving to $£ 32430 /$ QALY). Two studies reported metformin to not be cost effective (costing $>£ 20000$ per QALY): of these, one used a model substantially different in structure to other modelling studies included (the Archimedes model ${ }^{48}$ and the other was the first economic model of the USDPP. ${ }^{49}$ The subsequent models based on the USDPP and its follow-up study have found metformin to be cost saving or cost effective. ${ }^{40}$

Twelve studies compared lifestyle programmes and metformin directly. From a health system perspective, neither intervention appears more cost effective than the other with six studies reporting lifestyle programmes more cost effective than metformin, ${ }^{46} 4954575860$ five studies ${ }^{29} 40434755$ reporting metformin more cost effective than lifestyle programmes and one ${ }^{62}$ showing $<1 \%$ difference in cost-effectiveness between the two. However, from a societal perspective, metformin appears more cost effective than lifestyle programmes, with four ${ }^{40} 485862$ out of the five studies undertaking this analysis finding metformin more cost effective. This is because the cost of participants' time travelling to and attending lifestyle programme sessions is included in most calculations of 


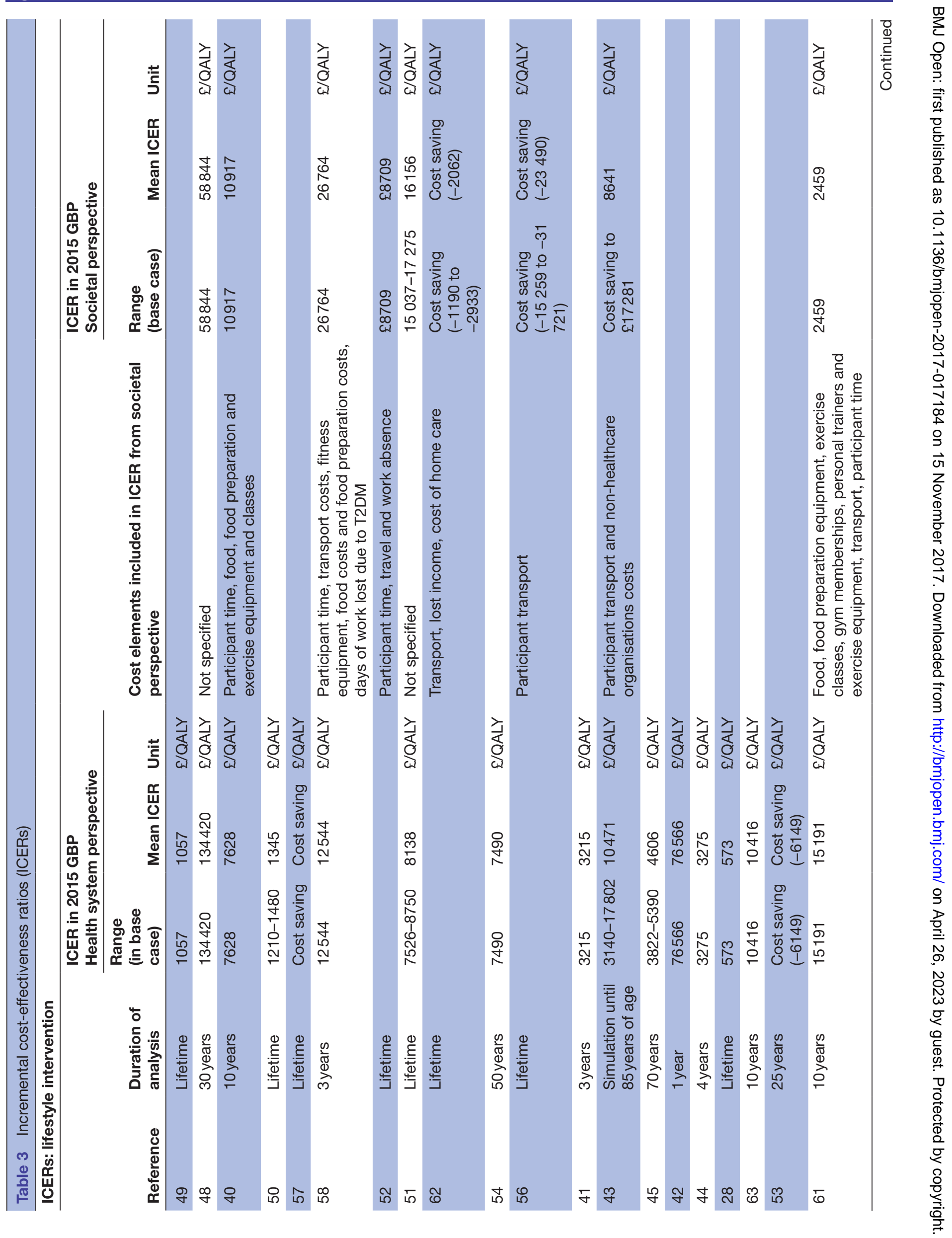




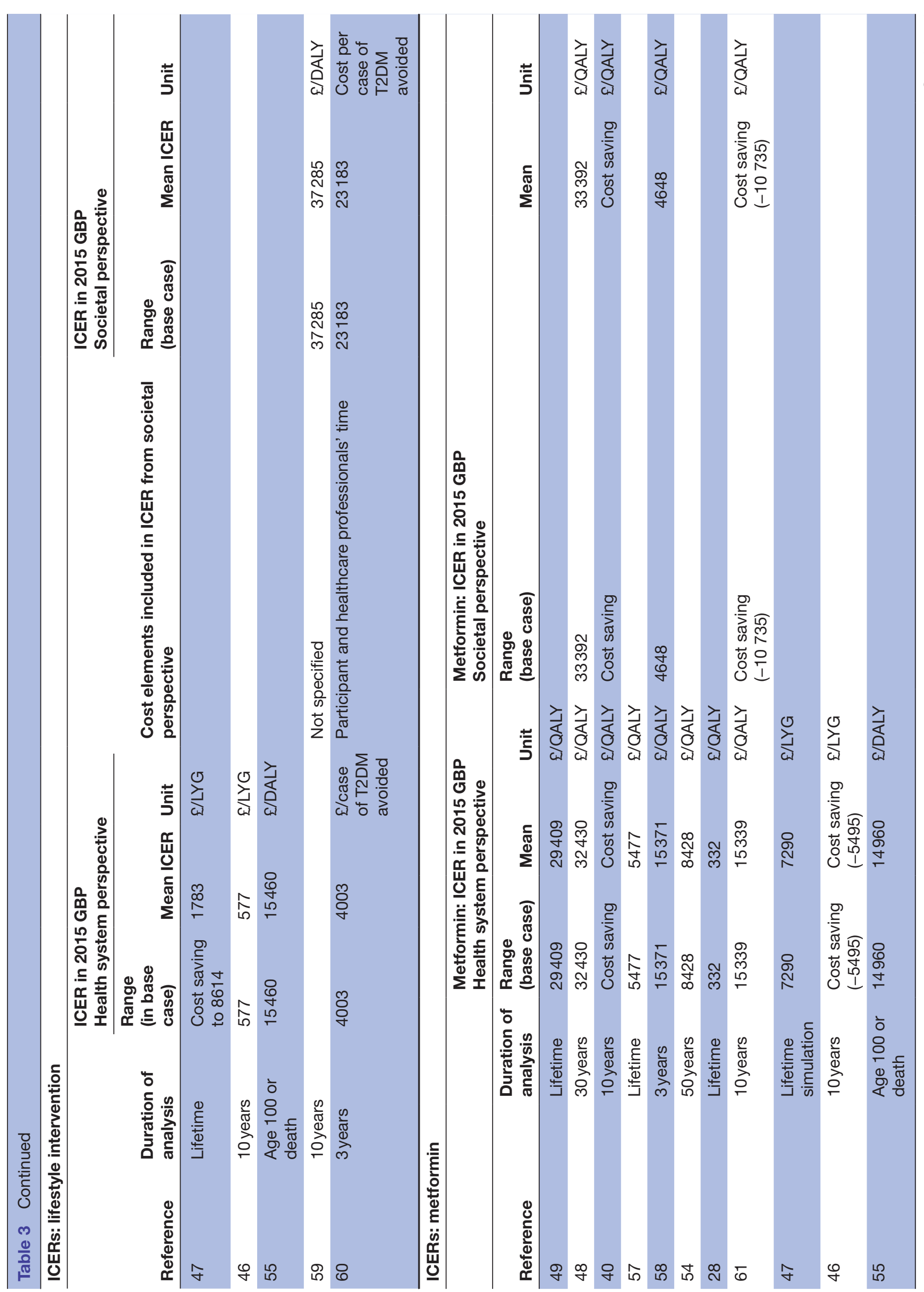

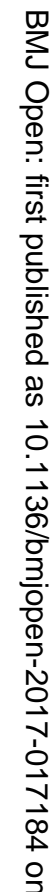

$\vec{v}$

¿ั

$\frac{\mathbb{1}}{3}$

ำ

ำ

흥

$\frac{\approx}{\varnothing}$

훙

害

흘. 
cost from a societal perspective, but not from a health system perspective.

Given the range of screening and lifestyle interventions provided, and the range of cost-effectiveness ratios, studies which reported ICERs as £/QALY from a health system perspective were grouped on a number of dimensions to identify key drivers of differences. The analyses revealed that:

1. Screening plus intervention studies tended to be less cost effective than intervention-only studies on average, but both approaches were associated with a wide range of ICERs highlighting current uncertainties. Of the 10 studies that reported £/QALY from a health system perspective for intervention-only studies, the median ICER was £4606/QALY (range: cost saving to $£ 134420$ /QALY). And the median ICER for the eight screening-plus-intervention studies was $£ 7814 / \mathrm{QALY}$ (range: $£ 573-76566 /$ QALY).

2. In general, the longer the period evaluated the more cost effective the interventions appeared. Studies that measured cost-effectiveness over a period of $\geq 25$ years appeared more cost effective (median ICER: £2976/ QALY) than studies that measured cost-effectiveness over $\leq 10$ years (median ICER: £10 416).

3. There was insufficient evidence to conclude whether lifestyle programmes with a duration of $<2$ years, 2-6 years or $>6$ years were more or less cost effective: Of the nine studies that included lifestyle programmes with a duration of $>2$ years and $<6$ years, the median ICER was £3275/QALY (range: cost saving to £134 420/QALY). Three studies included interventions $<2$ years duration with a wide variety of results (ICERs of £3215 [43], £10 471 [45] and £76 566 [44]). And three reported interventions of $>6$ years duration with a median ICER of $£ 7628 /$ QALY (range: cost saving to $£ 15$ 191/QALY).

4. There was insufficient evidence to conclude whether higher frequency of contact during 'core sessions' was more or less cost effective: Of the 11 studies that included lifestyle programmes with $\geq 16$ core sessions, the median ICER was $£ 7628 /$ QALY (range: cost saving to $£ 134420 /$ QALY). Three studies reported $£ /$ QALYs for lifestyle programmes with $<16$ core sessions with widely varying results (ICERs of £3215 [43], $£ 3275$ [46] and £76 566 [44]).

5. There was insufficient evidence to conclude whether group or individual core sessions were more or less cost effective: Of the 11 studies that included the core component of the lifestyle programme delivered on an individual basis, the median ICER was £7628/ QALY (range: cost saving to $£ 134420 /$ QALY). Three studies included lifestyle programmes where the core component was delivered in groups with a wide range of results (ICERs of $£ 6214$ [55], £3215 [43], £3275 [46] and £76 566 [44]).

There were insufficient studies in each group to conduct cost-effectiveness subgroup analysis by type of pre-diabetes. However, our meta-analysis of intervention 


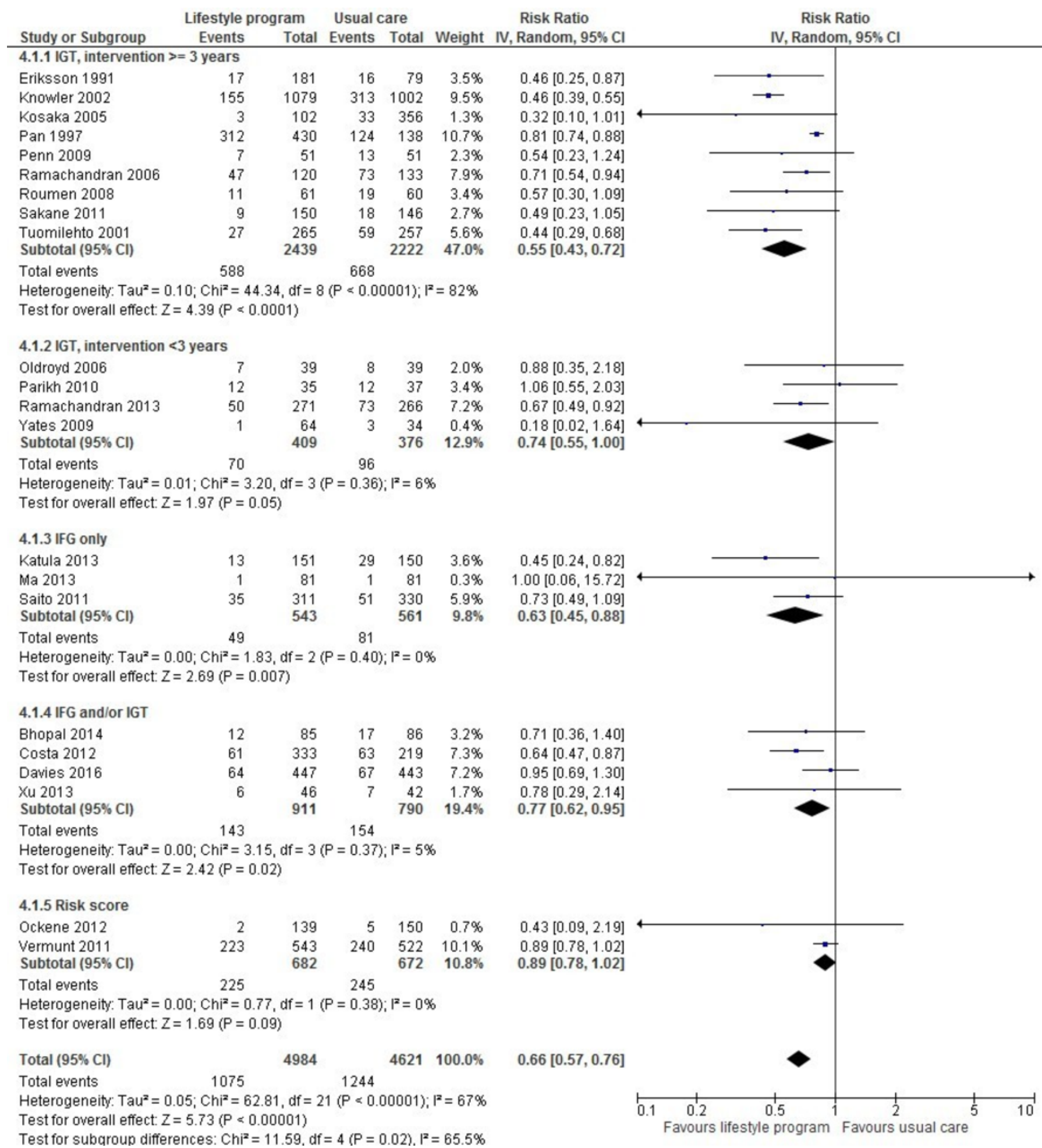

Figure 2 Lifestyle programme's effect on diabetes incidence. ${ }^{15-1867-86}$ IFG, impaired fasting glucose; IGT, impaired glucose tolerance.

trials suggests that this may be an important factor. Meta-analysis of intervention trials ${ }^{15-18}{ }^{66-86}$ (figure 2) showed that lifestyle interventions $\geq 3$ years duration for participants with IGT reduced the relative risk of developing diabetes by $45 \%$ (95\% CI $28 \%$ to $57 \%$ ). Lifestyle interventions lasting $<3$ years in participants with IGT showed a $26 \%$ (95\% CIs $0 \%$ to $45 \%$ ) relative risk reduction. There were insufficient studies to divide participants identified by other diagnostic criteria by duration of intervention. But for all studies that identified participants by IFG alone, IFG or IGT and presence of risk factors, the relative risk of diabetes was reduced by $37 \%$ ( $95 \%$ CI $12 \%$ to $55 \%$ ), $23 \%$ (95\% CI $5 \%$ to $38 \%$ ) and $11 \%$ ( $95 \%$ CI $-0.2 \%$ to $22 \%$ ), respectively. No 
studies used HbAlc alone as the diagnostic criteria for selecting participants.

\section{Other measures impacting the 'value for money' judgement}

Cost-effectiveness analysis only measures cost and benefit of an intervention for an individual participant. Policymakers, who are responsible for overall health budgets and the health of the population as a whole, may consider other measures (such as budget impact, impact on equity and impact on incident cases of the disease) when evaluating the impact of an intervention. In terms of budget impact, three studies ${ }^{45} 5960$ estimated the cost of implementing a national diabetes prevention programme to be between $0.13 \%$ and $0.2 \%$ of annual national health expenditure in the Netherlands, Germany and Australia. Two studies 5359 modelled annual expenditures for lifestyle programmes, showing that net savings only exceeded net expenditures 9-14 years after initiating the prevention programme.

Failure to attend screening, enrol in an intervention or comply with an intervention means that the number of cases of diabetes prevented is lower than might be anticipated when extrapolating from trials. As a result of these factors, as well as the partial and finite impact of interventions, two studies ${ }^{4560}$ estimated that only $0.1 \%-1.6 \%$ of cases of diabetes would be prevented by a population-wide programme in the Netherlands and a region of Germany. As an example of how this population-wide impact is calculated, Icks ${ }^{60}$ calculated that $29 \%$ of incident cases of diabetes in 3 years would be due to people with pre-diabetes (defined as IGT in this study). Of this pre-diabetic population, $30 \%$ of people would attend the screening test (oral glucose tolerance test (OGTT)), $40 \%$ and $59 \%$ would participate in the lifestyle intervention and metformin, respectively. In total, $32 \%$ of these would develop diabetes in 3 years with no intervention and $9.3 \%$ and $28.8 \%$ would develop diabetes with lifestyle and metformin respectively which resulted in $0.2 \%$ of incident cases of diabetes being prevented by metformin and $0.8 \%$ by lifestyle programmes. These rates of attendance and enrolment are based on best estimates, a recent systematic review found significant variation in participation rates seen in studies of lifestyle programmes. $^{87}$

\section{Quality, relevance/applicability and credibility of existing} economic evaluations for current healthcare decision-making Evaluation of studies against ISPOR's Questionnaire to Assess Relevance and Credibility of Modelling studies for Healthcare Decision Making ${ }^{30}$ (online supplementary appendix 5) raised a number of issues. The most important of these for policymakers are outlined below. No studies were excluded on the basis of this evaluation.

\section{Relevance/applicability of included studies (table 4)}

Given the variety of lifestyle programmes and range of different types of pre-diabetes, we examined the extent to which the included studies reflect national guidance in the $\mathrm{UK}^{88} 89$ and the USA, ${ }^{921}$ and the areas in which they differ.
Health system context

In total, 24 out of 27 studies were undertaken in high-income, predominantly Caucasian nations. Only two studies $^{62} 64$ were undertaken in developing countries, China and India.

\section{Target population}

Only $6^{29} 4252535663$ out of 27 studies used diagnostic tests for pre-diabetes that are in line with current UK guidance, that is, HbAlc or fasting plasma glucose. The majority of studies, 16 out of 27 , included participants with a positive oral glucose tolerance test (with or without fasting blood glucose). Prevalence differs between different types of pre-diabetes, with the potential to have a large impact on budgets. For example, one study in this review ${ }^{51}$ compared the cost-effectiveness of different diagnostic tests and found that expanding the definition of pre-diabetes from IGT and IFG to IFG or IGT increased the number of eligible participants threefold, with the savings from reduced diabetes incidence insufficient to offset the increase in cost, with a resulting small reduction in cost-effectiveness.

\section{Type of intervention}

In total, 21 of the 27 studies evaluated intensive trial-based interventions or intensive translations of trial interventions, which reflect current ADA guidance (lifestyle interventions modelled on the USDPP, targeting $7 \%$ wt loss).${ }^{9}$ However, reviews of community translations of the USDPP trial showed that while these translational programmes cost less to implement they were also less effective. ${ }^{19} 20$ The modelling studies based on the USDPP trial data may therefore not be relevant comparators for a USDPP-based community programme. In contrast, NICE in the UK and the Community Preventative Services Task Force in the USA advocate a more pragmatic approach to lifestyle programmes. Only three studies ${ }^{41-43}$ in this review are relevant comparators in terms of duration and intensity of lifestyle intervention and they report a wide range of cost-effectiveness (from $£ 3215 /$ QALY to $£ 76566 /$ QALY). One study ${ }^{42}$ (ICER $£ 76$ 566) was an in-trial cost-utility analysis over 1 year, therefore was unable to quantify the impact of the prevention programme on diabetes incidence. And one ${ }^{41}$ assumed treatment effects equivalent to those seen in a trial of an intensive lifestyle programme.

\section{Credibility of included studies}

Two key issues emerged with the assessment of the credibility of the modelling studies included in this review: (1) areas where updated evidence is available that may impact the evaluation and (2) areas where uncertainty persists and a range of assumptions are observed.

\section{Availability of updated meta-analyses}

In total, 12 of the 21 modelling studies assumed reductions in diabetes incidence equivalent to that achieved in the USDPP or Finnish Diabetes Prevention Study trials (relative risks of 0.50 at 3 years and 0.40 at 6 years respectively). However, two recent meta-analyses of randomised controlled trials ${ }^{3738}$ have shown a relative risk of diabetes 
Table 4 Relevance of included studies (numbers refer to the number of studies in this review in each category)

\begin{tabular}{lllllllll}
\hline \multicolumn{10}{c}{ Health system context } \\
\hline & USA & UK & Europe & Australia & Canada & Singapore & India & China \\
\hline $\begin{array}{l}\text { Which health } \\
\text { system? }\end{array}$ & 3 & 8 & 3 & 2 & 1 & 1 & 1 \\
\hline
\end{tabular}

\begin{tabular}{|c|c|c|c|c|c|c|}
\hline \multicolumn{7}{|c|}{ Target population } \\
\hline & IGT ( \pm IFG) & IFG & IFG or IGT & HbA1c & $\begin{array}{l}\text { Other (eg, risk } \\
\text { score) }\end{array}$ & $\begin{array}{l}\text { Current } \\
\text { guidance }\end{array}$ \\
\hline
\end{tabular}

\begin{tabular}{|c|c|c|c|c|}
\hline \multicolumn{5}{|c|}{ Type of intervention/s evaluated } \\
\hline & $\begin{array}{l}\text { Trial-based lifestyle } \\
\text { programme }\end{array}$ & $\begin{array}{l}\text { Pragmatic lifestyle } \\
\text { programme }\end{array}$ & $\begin{array}{l}\text { Not } \\
\text { stated }\end{array}$ & Current guidance \\
\hline
\end{tabular}

IFG, impaired fasting glucose; IGT, impaired glucose tolerance.

Sources: ADA: Standards of Medical Care in Diabetes, ${ }^{9}$ UK: NICE guidance,$^{88}$ USA: Community Preventative Services Task Force recommendations. ${ }^{21}$

Some studies may be included in more than one category, for example, if the study took place across multiple countries or used multiple diagnostic tests.

of 0.59 and 0.64 . And a meta-analysis of pragmatic lifestyle interventions ${ }^{39}$ excluding large trials showed a relative risk of 0.74 . The higher the relative risk, the less the effect of the intervention; therefore, these recent meta-analyses suggest that models based on DPP or DPS trial data will overstate the impact of interventions.

\section{Key uncertainties regarding modelling assumptions}

First, uncertainty remains over the extent to which the reduction in diabetes incidence persists once the intervention has ended. Studies included in this review made a wide range of assumptions on this point, ranging from no effect after the intervention ended to effects persisting until the participant developed type 2 diabetes or died. One recent meta-analysis ${ }^{37}$ showed relative risks of 0.80 at up to 20 years follow-up. However, this analysis includes predominantly the large trials (USDPP, Finnish DPS lifestyle programme and Da Qing) as long-term follow-up data are not available on community-based translational studies. Therefore, this relative risk likely overstates the long-term benefits of interventions outside the trial context. Second, uncertainty persists over the percentage of people that fail to enrol in lifestyle interventions following screening. Reflecting this uncertainty, five studies included in this review assumed $100 \%$ enrolment, two assumed between $50 \%$ and $99 \%$ and five assumed $<50 \%$ enrolment. A recent systematic review ${ }^{87}$ found that enrolment in interventions varies widely (from $0.28 \%$ to $100 \%$ ) depending on method of communication, setting and type of intervention. Finally, based on included studies, the relationship between the type of pre-diabetes and cost-effectiveness of the study is unclear. A factor which may be important given the differences in relative risk reductions illustrated by our meta-analysis.

\section{DISCUSSION}

\section{Principal findings}

This systematic review of economic evaluations of diabetes prevention programmes has produced seven major findings. First, that numerous economic evaluations have been undertaken in 15 different countries and produced diverse results due to differences in model structure and 
parameter values and to differences in health systems, types of pre-diabetes and types of lifestyle interventions included. Second, that the majority of evaluations relate to intensive trial-based interventions in populations in high-income countries identified with the oral glucose tolerance test. Third, that with these caveats in mind, both metformin and lifestyle interventions in people with pre-diabetes appear to be cost effective but not cost saving despite their impact on reducing diabetes incidence, with median ICERs of $£ 8428$ / QALY and $£ 7490 /$ QALY, respectively. To place this figure in context, smoking cessation services are estimated by NICE to have ICERs ranging from cost saving to $£ 984 / \mathrm{QALY}^{90}$ and breast cancer screening is estimated to have an ICER of $£ 20$ 800/QALY by the UK Panel on Breast Cancer Screening. ${ }^{91}$ The fact that diabetes prevention programmes are not cost saving is not due solely to the issue of discounting, as three studies $^{40} 5462$ report undiscounted cost-effectiveness ratios with only one of those appearing cost saving. Fourth, that metformin and lifestyle programmes appear equally cost effective when only the costs of the health system are taken into account, but metformin is more cost effective when costs of participants' time (participating in and travelling to programme activities) are taken into account. Fifth, screening-plus-intervention programmes were less cost effective on average than intervention-only programmes. But both approaches were associated with a wide range of cost-effectiveness ratios and the population benefit of screening in identifying people with previously undiagnosed pre-diabetes is not taken into account in a cost-effectiveness calculation. Sixth, there is insufficient evidence to deduce what intensity, duration or format or lifestyle programmes are more cost effective than others. Finally, programmes that evaluated costs and benefits over $\geq 25$ years were more cost effective than those that looked at $\leq 10$ years.

\section{Implications for policymakers}

Both the type of pre-diabetes and the type of lifestyle programme have a substantial impact on the number of cases of diabetes that are delayed or prevented. Guidance in the UK and the USA advocate lower-intensity 'pragmatic' lifestyle programmes and there is a small amount of evidence that these are cost effective. In light of recent meta-analyses, historical studies are likely overstating treatment effects and uncertainty over duration of impact limits accurate long-term modelling. Guidance in the UK advocates the use of fasting plasma glucose or HbAlc in identifying people with pre-diabetes. There is currently insufficient data to conclude that interventions in people identified solely with $\mathrm{HbA1c}$ are cost effective, and no randomised controlled trials with HbAlc as the inclusion criteria to enable estimation of treatment effects. There is insufficient evidence to suggest that metformin is more cost effective than lifestyle programmes.

Policymakers need to make decisions even when all the evidence is not available, as is the case with the English national diabetes prevention programme (Healthier You: The NHS DPP ${ }^{22}$ which provides low-intensity lifestyle programmes to people with IFG and or high HbAlc. In this case, rigorous evaluation alongside policy implementation could add to the evidence base, examining (1) what reduction in relative risk is associated with a large-scale implementation of a low-intensity lifestyle programme? (2) how does this reduction in risk attenuate over time? (3) how does reduction in relative risk differ by type of pre-diabetes?

In addition to these considerations of cost-effectiveness, policymakers may need to balance impact on health budgets, incident cases of diabetes and equity of healthcare provision. In the few studies where these were modelled, budget impact was moderate (prevention programmes required $0.13 \%-0.2 \%$ of respective countries total healthcare budget), financial payoffs were delayed (net expenditure on treatment and prevention of diabetes only declined after 9-14 years) and impact on incident cases of diabetes was limited $(0.1 \%-1.6 \%$ reduction in incident cases). This suggests that other avenues to reducing incident cases of diabetes will need to be explored if substantial inroads are to be made in controlling the diabetes 'epidemic'. These may include population-wide measures to address obesity, a primary determinant of progression to type 2 diabetes in a person with pre-diabetes. ${ }^{92}$

\section{Comparison with previous systematic reviews}

Our findings confirm those of previous systematic reviews which have shown that lifestyle interventions are generally cost effective, but with a wide range of cost-effectiveness ratios, reflecting heterogeneity of interventions, target populations and modelling approaches. They have shown that lifestyle interventions appear more cost effective if group, rather than individual sessions, are provided and a long time horizon is adopted for analysis. They have raised the issue of the limited number of studies in low-income andmiddle-income countries, the concern that real-life implementation of programmes will be less effective than trial-based interventions, and the uncertainty that persists regarding long-term efficacy of these interventions. This review has added to previous work in three key areas: evaluation of metformin, comparison of screening-plus-intervention against intervention-only studies and consideration of the relevance and credibility of studies for decision makers.

\section{SUGGESTIONS FOR FURTHER RESEARCH}

This study has identified three areas where further research would be beneficial. First, developing an understanding of how people with different types of pre-diabetes respond to interventions and the subsequent cost-effectiveness profiles for different diagnostic-treatment combinations. This could be undertaken in both modelling studies, using recent evidence from meta-analyses, or retrospective analysis of existing trial data where different types of pre-diabetes may coexist (eg, IGT and HbA1c, IGT and IFG or IGT-only participants). Second, long-term follow-up studies of pragmatic lifestyle intervention programmes are important to understand the duration of impact on diabetes incidence following cessation of the intervention; uncertainty in this 
area limits the accuracy of long-term modelling studies. Finally, consideration of the role of broader social and environmental programmes (eg, sugar tax, increasing active travel) on diabetes incidence will be important as, based on studies in this review, individual lifestyle programmes and metformin are unlikely to be sufficient to address the vast majority of incident cases of diabetes.

\section{CONCLUSIONS}

National diabetes prevention guidance in the UK and USA advocates pragmatic lifestyle programmes $(<3$ years in duration), and in the UK the use of HbAlc or fasting plasma glucose is recommended for diagnosing pre-diabetes. However, the majority of cost-effectiveness studies relate to a different definition of pre-diabetes and a higher intensity of intervention, which limits the direct applicability of findings. In the few studies that evaluated other economic considerations, budget impact of prevention programmes was moderate, financial payoffs were delayed and impact on incident cases of diabetes was limited. There remains a need for long-term economic evaluation of programmes that reflect current policy and consideration of the role of broader social and environmental programmes on diabetes incidence.

Acknowledgements The authors thank Newham Clinical Commissioning Group and University College Partners for their support of this project.

Contributors SR and EB conceptualised the paper. SR led the data extraction and analysis and drafted the paper. EB and SR undertook the searches. MA, GB and DC were all advisers, and TG was the principal supervisor, on the DPhil of which this study forms a part. EB checked the data extraction. All authors have seen and approved the final manuscript. All authors had full access to all of the data in the study and can take responsibility for the integrity of the data and the accuracy of the data analysis. The lead author (the manuscript's guarantor) affirms that the manuscript is an honest, accurate and transparent account of the study being reported; that no important aspects of the study have been omitted; and that any discrepancies from the study as planned have been explained.

Competing interests None declared.

Provenance and peer review Not commissioned; externally peer reviewed.

Data sharing statement № additional data available.

Open Access This is an Open Access article distributed in accordance with the Creative Commons Attribution Non Commercial (CC BY-NC 4.0) license, which permits others to distribute, remix, adapt, build upon this work non-commercially, and license their derivative works on different terms, provided the original work is properly cited and the use is non-commercial. See: http://creativecommons.org/ licenses/by-nc/4.0/

(c) Article author(s) (or their employer(s) unless otherwise stated in the text of the article) 2017. All rights reserved. No commercial use is permitted unless otherwise expressly granted.

\section{REFERENCES}

1. IDF. International Diabetes Federation Diabetes Atlas. 7th edn: International Diabetes Federation (IDF), 2015.

2. Wild S, Roglic G, Green A, et al. Global prevalence of Diabetes: estimates for the year 2000 and projections for 2030. Diabetes Care 2004;27:1047-53.

3. WHO. 2016. Diabetes Fact Sheet. http://www.who.int/mediacentre/ factsheets/fs312/en/.

4. Alberti K, Zimmett P; Shaw International Diabetes Federation. A consensus on type 2 Diabetes Prevention. Diabet Med 2007;24:451-63.
5. Zimmet P, Alberti KG, Shaw J. Global and societal implications of the diabetes epidemic. Nature 2001;414:782-7.

6. Bagust A, Hopkinson PK, Maslove L, et al. The projected health care burden of type 2 diabetes in the UK from 2000 to 2060. Diabet Med 2002;19:1-5.

7. Yudkin JS, Montori VM. The epidemic of pre-diabetes: the medicine and the politics. BMJ 2014;349:94485.

8. World Health Organization. 2011. Use of glycated haemoglobin $(\mathrm{HbA} 1 \mathrm{c})$ in the diagnosis of diabetes mellitus. Geneva: World Health Organization.

9. American Diabetes Association. Standards of Medical Care in Diabetes 2016. Diabetes Care 2016;39:1653.

10. International Expert Committee. International Expert Committee report on the role of the $\mathrm{A} 1 \mathrm{C}$ assay in the diagnosis of diabetes. Diabetes Care 2009;32:1327-34.

11. Faerch K, Borch-Johnsen K, Holst JJ, et al. Pathophysiology and aetiology of impaired glucose tolerance: does it matter for treatment and prevention of type 2 diabetes. Diabetologica 2009;52:1714-23.

12. Morris DH, Khunti K, Achana F, et al. Progression rates from $\mathrm{HbA1c}$ 6.0-6.4\% and other prediabetes definitions to type 2 diabetes: a meta-analysis. Diabetologia 2013;56:1489-93.

13. Diabetes Prevention Program Research Group. HbA1c as a predictor of diabetes and as an outcome in the diabetes prevention program: a randomized clinical trial. Diabetes Care 2014

14. Noble D, Mathur R, Dent T, et al. Risk models and scores for type 2 diabetes: systematic review. BMJ 2011;343:d7163.

15. Knowler WC, Barrett-Connor E, Fowler SE, et al. Reduction in the incidence of type 2 diabetes with lifestyle intervention or metformin. N Engl J Med 2002;346:393-403.

16. Lindström J, Louheranta A, Mannelin M, et al. The Finnish Diabetes Prevention Study (DPS): Lifestyle intervention and 3-year results on diet and physical activity. Diabetes Care 2003;26:3230-6.

17. Pan XR, Li GW, Hu YH, et al. Effects of diet and exercise in preventing NIDDM in people with impaired glucose tolerance. The Da Qing IGT and diabetes study. Diabetes Care 1997;20:537-44.

18. Ramachandran A, Snehalatha C, Mary S, et al. The Indian Diabetes Prevention Programme shows that lifestyle modification and metformin prevent type 2 diabetes in Asian Indian subjects with Impaired glucose tolerance (IDPP-1). Diabetologia 2006;49:289-97.

19. Ali MK, Echouffo-Tcheugui J, Williamson DF. How effective were lifestyle interventions in real-world settings that were modeled on the Diabetes Prevention Program? Health Aff 2012;31:67-75.

20. Kahn R, Davidson MB. The reality of type 2 diabetes prevention. Diabetes Care 2014;37:943-9.

21. The Community Guide. 2014. Diabetes prevention and control: combined diet and Physical Activity Promotion Programmes to prevent type 2 diabetes among people at increased risk. Atlanta, GA: Community Preventive Services Task Force. www.thecommunityguide.org/diabetes/supportingmaterials/ SScombineddietandpa-econ.html (accessed 19 Apr 2015).

22. The NHS Diabetes Prevention Program. https://www.england.nhs.uk/ ourwork/qual-clin-lead/diabetes-prevention/ (accessed 19 Apr 2015).

23. Alouki K, Delisle H, Bermúdez-Tamayo C, et al. Lifestyle interventions to prevent type 2 Diabetes: a Systematic Review of Economic Evaluation Studies. J Diabetes Res 2016;2016:1-14.

24. Saha S, Gerdtham UG, Johansson P. Economic evaluation of lifestyle interventions for preventing diabetes and cardiovascular diseases. Int J Environ Res Public Health 2010;7:3150-95.

25. Li R, Zhang P, Barker LE, et al. Cost-effectiveness of interventions to prevent and control diabetes mellitus: a systematic review. Diabetes Care 2010;33:1872-94.

26. Li R, Qu S, Zhang P, et al. Economic evaluation of combined diet and physical activity promotion programs to prevent type 2 diabetes among persons at increased risk: a systematic review for the community preventive services task force. Ann Intern Med 2015;163:452-60.

27. Radl KI, lanuale C, Boccia S. A systematic review of the costeffectiveness of lifestyle modification as primary prevention intervention for diabetes mellitus type 2. Epidemiol Biostat Public Health 2013;10:2.

28. Schaufler TM, Wolff M. Cost effectiveness of preventive screening programmes for type 2 diabetes mellitus in Germany. Appl Health Econ Health Policy 2010;8:191-202.

29. Dall TM, Storm MV, Semilla AP, et al. Value of lifestyle intervention to prevent diabetes and sequelae. Am J Prev Med 2015;48:271-80.

30. Jaime Caro J, Eddy DM, Kan H, et al. Questionnaire to assess relevance and credibility of modeling studies for informing health care decision making: an ISPOR-AMCP-NPC good practice Task Force report. Value Health 2014;17:174-82.

31. Briggs A, Claxton K, Sculpher M. Decision modelling for health economic evaluation. Oxford, UK: Oxford University Press, 2006. 
32. Devlin N, Parkin P. Does NICE have a cost-effectiveness threshold and what other factors influence its decisions? A binary choice analysis. Health Econ https://www.city.ac.uk/_data/assets/pdf_file/ 0015/90501/0301 devlin-parkin.pdf (accessed 14 Oct 2016).

33. Grosse SD. Assessing cost-effectiveness in healthcare: history of the $\$ 50,000$ per QALY threshold. Expert Rev Pharmacoecon Outcomes Res 2008;8:165-78.

34. World Health Organisation. Macroeconomics and Health: investing in Health for Economic Development. Geneva.: World Health Organisation, 2001.

35. The 'CCEMG - EPPI-Centre Cost Converter. http://eppi.ioe.ac.uk/ costconversion/default.aspx (accessed $20 \mathrm{Sep}$ 2016).

36. Curtis B, Burns A. Unit costs of Health and Social Care 2015 Personal Social Services Research Unit. http://www.pssru.ac.uk/ project-pages/unit-costs/2015/index.php (accessed 14 Oct 2016).

37. Barry E, Roberts S, Oke J, et al. Can type 2 diabetes be prevented using screen-and-treat policies? systematic review and metaanalysis of screening tests and interventions for pre-diabetes. BMJ 2017;4:6538.

38. Balk EM, Earley A, Raman G, et al. Combined diet and physical activity promotion programs to prevent type 2 diabetes among persons at increased risk: a systematic review for the community preventive services task force. Ann Intern Med 2015;163:437.

39. Ashra NB, Spong R, Carter P, et alA systematic review and Meta- analysis assessing the effectiveness of pragmatic lifestyle interventions for the prevention of type 2 diabetes mellitus in routine practiceLondonPublic Health England 2015. https://www.gov. uk/government/publications/diabetes-prevention-programmesevidence-review (accessed 1 Oct 2015).

40. Diabetes Prevention Program Research Group. The 10-year costeffectiveness of lifestyle intervention or metformin for diabetes prevention: an intent-to-treat analysis of the DPP/DPPOS. Diabetes Care 2012;35:723-30.

41. Smith KJ, Hsu HE, Roberts MS, et al. Cost-effectiveness analysis of efforts to reduce risk of type 2 diabetes and cardiovascular disease in southwestern Pennsylvania, 2005-2007. Prev Chronic Dis 2010;7:A109

42. Irvine L, Barton GR, Gasper AV, et al. Cost-effectiveness of a lifestyle intervention in preventing type 2 diabetes. Int $J$ Technol Assess Health Care 2011;27:275-82.

43. Feldman I, Hellström L, Johansson P. Heterogeneity in costeffectiveness of lifestyle counseling for metabolic syndrome risk groups -primary care patients in Sweden. Cost Eff Resour Alloc 2013;11:19.

44. Sagarra R, Costa B, Cabré JJ, et al. Lifestyle interventions for diabetes mellitus type 2 prevention. Rev Clin Esp 2014;214:59-68.

45. Jacobs-van der Bruggen MA, Bos G, Bemelmans WJ, et al. Lifestyle interventions are cost-effective in people with different levels of diabetes risk: results from a modeling study. Diabetes Care 2007;30:128-34.

46. Caro JJ, Getsios D, Caro I, et al. Economic evaluation of therapeutic interventions to prevent type 2 diabetes in Canada. Diabet Med 2004;21:1229-36.

47. Palmer AJ, Roze S, Valentine WJ, et al. Intensive lifestyle changes or metformin in patients with impaired glucose tolerance: modeling the long-term health economic implications of the diabetes prevention program in Australia, France, Germany, Switzerland, and the United Kingdom. Clin Ther 2004;26:304-21.

48. Eddy DM, Schlessinger L, Kahn R. Clinical outcomes and costeffectiveness of strategies for managing people at high risk for diabetes. Ann Intern Med 2005;143:251-64.

49. Herman WH, Hoerger TJ, Brandle M, et al. The cost-effectiveness of lifestyle modification or metformin in preventing type 2 diabetes in adults with impaired glucose tolerance. Ann Intern Med 2005;142:323-32.

50. Ackermann RT, Marrero DG, Hicks KA, et al. An evaluation of cost sharing to finance a diet and physical activity intervention to prevent diabetes. Diabetes Care 2006;29:1237-41.

51. Hoerger TJ, Hicks KA, Sorensen SW, et al. Cost-effectiveness of screening for pre-diabetes among overweight and obese U.S. adults. Diabetes Care 2007;30:2874-9.

52. Lindgren P, Lindström J, Tuomilehto J, et al. Lifestyle intervention to prevent diabetes in men and women with impaired glucose tolerance is cost-effective. Int $J$ Technol Assess Health Care 2007:23:177-83.

53. Zhuo X, Zhang P, Gregg EW, et al. A nationwide community-based lifestyle program could delay or prevent type 2 diabetes cases and save $\$ 5.7$ billion in 25 years. Health Aff 2012;31:50-60.

54. Gillies CL, Lambert PC, Abrams KR, et al. Different strategies for screening and prevention of type 2 diabetes in adults: cost effectiveness analysis. BMJ 2008;336:1180-5.
55. Bertram MY, Lim SS, Barendregt JJ, et al. Assessing the costeffectiveness of drug and lifestyle intervention following opportunistic screening for pre-diabetes in primary care. Diabetologia 2010;53:875-81.

56. Neumann A, Schwarz P, Lindholm L. Estimating the costeffectiveness of lifestyle intervention programmes to prevent diabetes based on an example from Germany: markov modelling Cost Eff Resour Alloc 2011;9:17.

57. Palmer AJ, Tucker DM. Cost and clinical implications of diabetes prevention in an Australian setting: a long-term modeling analysis. Prim Care Diabetes 2012;6:109-21.

58. Png ME, Yoong JS. Evaluating the cost-effectiveness of lifestyle modification versus metformin therapy for the prevention of diabetes in Singapore. PLoS One 2014:9:e107225.

59. Colagiuri S, Walker AE. Using an economic model of diabetes to evaluate prevention and care strategies in Australia. Health Aff 2008;27:256-68.

60. Icks A, Rathmann W, Haastert B, et al. Clinical and cost-effectiveness of primary prevention of type 2 diabetes in a 'real world' routine healthcare setting: model based on the KORA survey 2000. Diabet Med 2007;24:473-80.

61. Herman WH, Edelstein SL, Ratner RE, et al. Effectiveness and costeffectiveness of diabetes prevention among adherent participants. Am J Manag Care 2013;19:194-202.

62. Liu X, Li C, Gong H, et al. An economic evaluation for prevention of diabetes mellitus in a developing country: a modelling study. BMC Public Health 2013;13:729.

63. Mortaz S, Wessman C, Duncan R, et al. Impact of screening and early detection of impaired fasting glucose tolerance and type 2 diabetes in Canada: a Markov model simulation. Clinicoecon Outcomes Res 2012;4:91-7.

64. Ramachandran A, Snehalatha C, Yamuna A, et al. Costeffectiveness of the interventions in the primary prevention of diabetes among Asian Indians: within-trial results of the Indian Diabetes Prevention Programme (IDPP). Diabetes Care 2007;30:2548-52.

65. Sculpher MJ, Pang FS, Manca A, et al. Generalisability in economic evaluation studies in healthcare: a review and case studies. Health Technol Assess 2004;8:1-192.

66. Daniels N, Porteny T, Urritia J. Expanded HTA: enhancing fairness and legitimacy. Int $J$ Health Policy Manag 2016;5:1-3.

67. Yates T, Davies M, Gorely T, et al. Effectiveness of a pragmatic education program designed to promote walking activity in individuals with impaired glucose tolerance: a randomized controlled trial. Diabetes Care 2009;32:1404-10.

68. Parikh P, Simon EP, Fei K, et al. Results of a pilot Diabetes Prevention intervention in East Harlem, New York City: project HEED. Am J Public Health 2010;100:S232-39.

69. Iqbal Hydrie MZ, Basit A, Shera AS, et al. Effect of intervention in subjects with high risk of diabetes mellitus in Pakistan. $J$ Nutr Metab 2012;2012:867604:1-7.

70. Ramachandran A, Snehalatha C, Ram J, et al. Effectiveness of mobile phone messaging in prevention of type 2 diabetes by lifestyle modification in men in India: a prospective, parallelgroup, randomised controlled trial. Lancet Diabetes Endocrinol 2013;1:191-8.

71. Oldroyd JC, Unwin NC, White M, et al. Randomised controlled trial evaluating lifestyle interventions in people with impaired glucose tolerance. Diabetes Res Clin Pract 2006;72:117-27.

72. Penn L, White M, Oldroyd J, et al. Prevention of type 2 diabetes in adults with impaired glucose tolerance: the european Diabetes Prevention RCT in Newcastle upon Tyne, UK. BMC Public Health 2009;9:342.

73. Ramachandran A, Snehalatha C, Mary S, et al. The Indian Diabetes Prevention Programme shows that lifestyle modification and metformin prevent type 2 diabetes in Asian Indian subjects with impaired glucose tolerance (IDPP-1). Diabetologia 2006;49:289-97.

74. Roumen C, Corpeleijn E, Feskens EJ, et al. Impact of 3-year lifestyle intervention on postprandial glucose metabolism: the SLIM study. Diabet Med 2008;25:597-605.

75. Sakane N, Sato J, Tsushita K, et al. Prevention of type 2 diabetes in a primary healthcare setting: three-year results of lifestyle intervention in Japanese subjects with impaired glucose tolerance. BMC Public Health 2011;11:40.

76. Kosaka K, Noda M, Kuzuya T. Prevention of type 2 diabetes by lifestyle intervention: a Japanese trial in IGT males. Diabetes Res Clin Pract 2005;67:152-62.

77. Eriksson KF, Lindgärde F. Prevention of type 2 (non-insulindependent) diabetes mellitus by diet and physical exercise. the 6-year malmö feasibility study. Diabetologia 1991;34:891-8. 
78. Katula JA, Vitolins MZ, Morgan TM, et al. The healthy living partnerships to prevent diabetes study: 2-year outcomes of a randomized controlled trial. Am J Prev Med 2013;44:S324-32.

79. Ma J, Yank V, Xiao L, et al. Translating the Diabetes Prevention Program lifestyle intervention for weight loss into primary care: a randomized trial. JAMA Intern Med 2013;173:113-21.

80. Saito T, Watanabe M, Nishida J, et al. Lifestyle modification and prevention of type 2 diabetes in overweight japanese with impaired fasting glucose levels: a randomized controlled trial. Arch Intern Med 2011;171:1352-60.

81. Xu DF, Sun JQ, Chen M, et al. Effects of lifestyle intervention and meal replacement on glycaemic and body-weight control in chinese subjects with impaired glucose regulation: a 1-year randomised controlled trial. Br J Nutr 2013;109:487-92.

82. Bhopal RS, Douglas A, Wallia S, et al. Effect of a lifestyle intervention on weight change in South Asian individuals in the UK at high risk of type 2 diabetes: a family-cluster randomised controlled trial. Lancet Diabetes Endocrinol 2014;2:218-27.

83. Davies MJ, Gray LJ, Troughton J, et al. A community based primary prevention programme for type 2 diabetes integrating identification and lifestyle intervention for prevention: the let's prevent diabetes cluster randomised controlled trial. Prev Med 2016;84:48-56.

84. Costa B, Barrio F, Cabré JJ, et al. Delaying progression to type 2 diabetes among high-risk Spanish individuals is feasible in real-life primary healthcare settings using intensive lifestyle intervention. Diabetologia 2012;55:1319-28.

85. Ockene IS, Tellez TL, Rosal MC, et al. Outcomes of a latino community-based intervention for the prevention of diabetes: the
Lawrence Latino Diabetes Prevention Project. Am J Public Health 2012;102:336-42.

86. Vermunt PW, Milder IE, Wielaard F, et al. Lifestyle counseling for type 2 diabetes risk reduction in Dutch primary care: results of the APHRODITE study after 0.5 and 1.5 years. Diabetes Care 2011;34:1919-25.

87. Aziz Z, Absetz P, Oldroyd J, et al. A systematic review of real-world diabetes prevention programmes: learnings from the last 15 years implementation. Science 2015;10:172.

88. National Institute for Health and Care Excellence. 2012. Type 2 diabetes: prevention in people at high risk NICE Guideline PH 38. https://www.nice.org.uk/guidance/ph38 (accessed 20 Mar 2016).

89. National Institute of Clinical Excellence. 2012. Preventing type 2 diabetes: risk identification and interventions for individuals at high risk. https://www.nice.org.uk/guidance/ph38/resources/costingreport-68964013 (accessed 07 Sep 2016).

90. National Institute of Clinical Excellence. 2007. Cost effectiveness of interventions for smoking cessation: final report.

91. Pharoah PD, Sewell B, Fitzsimmons D, et al. Cost effectiveness of the NHS breast screening programme: life table model. BMJ 2013;346:f2618.

92. Cobiac LJ, Veerman L, Vos T. The role of cost-effectiveness analysis in developing nutrition policy. Annu Rev Nutr 2013;33:373-93.

93. National Institute of Clinical excellence.Glossary. https://www.nice. org.uk/Glossary (accessed 14 Oct 2016).

94. Robberstad B. QALYs vs DALYs vs LYs gained: what are the differences. and what difference do they make for health care priority setting? Norsk Epidemiologi 2005;15:183-91. 